shift patterns; feedback from service users of a telephone helpline; outcome measures; safer nursing toolkit; rehabilitative palliative care; dying phase implementation; record keeping and documentation; review of multi-disciplinary meeting. A planned event will celebrate the programme and share learning.

Conclusions The two-year programme has strengthened team working and created a culture of curiosity and continuous improvement.

\section{P-288 ESTABLISHING LINK NURSE ROLES TO ENHANCE LEADERSHIP, KNOWLEDGE AND DEVELOPMENT}

${ }^{1}$ Melanie Legg, 'Anne Cleary, 'Joanne Shackelton, ${ }^{2}$ Sylvie Hampton. ${ }^{1}$ Marie Curie, London, UK; ${ }^{2}$ Wound Care Consultants Ltd, UK

\subsection{6/bmispcare-2017-hospice.313}

Background The term 'Link Nurse' refers to nurses who are prepared to acts as links between specialist services and the staff/patients of the clinical areas where they work. Link Nurses are not specialist nurses but are nurses with a keen interest in the area. We have developed link nurse programmes for both infection control and tissue viability. The Link Nurse role is seen as a means of improving the quality of care delivered to patients through the development and education of the staff who provide 24 hour ongoing care at a direct level (Friedewald, 2009). The Link Nurse role within Marie Curie is particularly relevant to areas as we are a disperse organization with nine hospices and ten regions in which we deliver end of life care. Ensuring the consistency of key messages and development opportunities is essential to patients and their families/loved ones receiving the best possible care at end of life.

Aims

- To develop registered nurses skills in leadership and development of others as is expected from their professional code of conduct (NMC, 2015)

- To increase their knowledge in a specialist area so that they can provide and disseminate key information in relation to that topic

- To offer individualised development dependent on the individuals need

- To be a resource in the local area in which they are working.

Methods Registered Nurses identified with an interest in either infection control or tissue viability have undertaken quarterly development days, which have been led by the specialist infection control lead nurse and external tissue viability lead.

Results We are currently looking at the evaluation of these development programmes.

Conclusion The Link Nurse programmes are developing momentum and we see each nurse acting as a role model and visible advocate for their specialist interest (RCN, 2012). Communication and networking is vital to further development and understanding of these roles and the many benefits they bring including supporting audit and surveillance of key issues.

\section{P-289 WORKING TOGETHER, MAKING A DIFFERENCE - DEVELOPING A HOSPICE CULTURE}

Ann Smits, Jacqui Tomsett. Farleigh Hospice, Chelmsford, UK

\subsection{6/bmjspcare-2017-hospice.314}

Background The annual staff survey (Birdsong) in 2015 highlighted a drop in positive results, particularly in areas concerned with communication. Whilst staff were proud to work for the hospice $(90 \%)$ and would recommend a relative being cared for by the hospice (90\%), they highlighted poor communication across all departments and staff reported low morale and feeling stressed (62\%).

The results were discussed at all levels of the organisation and it was decided to:

- set up a staff/volunteer/management group to advise on all matters affecting staff

- look at organisational culture and develop a framework for hospice culture

- develop a communication strategy, including updating the website and the intranet.

Aim The aim of this project was to bring staff and volunteers together to develop and 'own' a framework for hospice culture that would enable the hospice to become a great place to work where staff are happy and motivated and work to our values.

Methods The new staff/volunteer/management group was formed in 2015, the Moving on Together group (MOTG). The group reviewed the literature on organisational culture and then developed a framework for the hospice culture. In addition to this work, in 2017, we have started a Leadership Programme and a series of workshops on resilience and stress. Results The new framework was presented to the Board and agreed. The communication strategy, website and intranet were developed. The 2016 annual staff survey showed an improvement in communication between teams of $8 \%$ and between staff and senior management of $10 \%$. Stress levels were about the same. The 2017 survey results will be out in August.

Conclusions The framework for hospice culture has been developed and is becoming embedded in the organisation. The work is in its infancy but there are signs that communication and morale are improving. We are keen to share this work with others.

\section{P-290 A VISION OF PERSON-CENTRED CULTURE (PCC) ACROSS THE HOSPICE: DO ALL EYES SEE THE SAME TRUTH?}

Tracy Smith, Brigid Lydon, Tracy Paton, Hilary Ford. Marie Curie, Edinburgh, UK

\subsection{6/bmjspcare-2017-hospice.315}

Background Over a two year period from 2015-2017, Queen Margaret University (QMU) facilitated a programme of practice development with a key group of multi-professional clinical and non-clinical staff. The Person-centred Practice Framework developed and updated by McCormack and McCance in 2016, continues to guide this on-going programme of work. 